\title{
Apoptosis as a mechanism of neuronal cell death following acute experimental spinal cord injury
}

\author{
J Lou, LG Lenke, FJ Ludwig and MF O’Brien \\ Department of Orthopaedic Surgery, Washington University School of Medicine, St. Louis, Missouri, USA
}

\begin{abstract}
The complex biochemical interactions following acute spinal cord injury have undergone considerable investigation recently. Progress has been made in discovering both primary and secondary injury cascades that combine to produce the ultimate neurologic insult. Traditionally, neuronal and supporting cell death following spinal cord injury have focused on necrotic death pathways resulting passively from the actual mechanical tissue damage and inflammatory processes which follow. However, the occurrence of programmed apoptotic cell death which is an actively mediated cellular process may occur following acute spinal cord injury and, if present, may play a role in the ultimate neurologic insult. In this study, we document a chronologically-specific course of apoptotic cell death by the TUNEL assay technique following an acute experimental spinal cord injury in the rat model. In this manner, apoptotic cell death following acute spinal cord injury may play a pivotal role in the secondary injury cascade which produces the ultimate neurologic insult and may allow potential for mediating neuronal survival via anti-apoptotic factors such as the protooncogene Bcl-2.
\end{abstract}

Keywords: apoptosis; acute spinal cord injury; secondary injury; neuronal death

\section{Introduction}

Acute spinal cord injury is still a devastating and often permanent condition of neurologic injury with many physical, psychological and social ramifications. ${ }^{1}$ Much research has focused recently upon analyzing the cellular and molecular components of acute spinal cord injury to better understand the processes that produce permanent neurologic injury. It has been confirmed that two separate components combine to produce neurologic damage in acute spinal cord injury: the primary and secondary injuries. ${ }^{2,3}$ The primary mediators of spinal cord injury include the actual mechanical tissue disruption which causes cellular release of electrocytes, metabolites and lysozymes from injured neuronal tissues. ${ }^{3-5}$ This primary injury cascade is a passive process that occurs immediately following the traumatic event.

It is now commonly agreed that a secondary injury cascade follows which appears mediated by cellular and molecular processes working through complex mechanisms. ${ }^{3-7}$ Recent research has focused upon various secondary mediators of tissue injury including edema, inflammation, growth factors, ischemia, reperfusion, calcium complexes, superoxide radicals, and other reactive oxygen species. ${ }^{8-12}$ This complex secondary injury cascade appears to be actively mediated and has shown some promise for experi-

Correspondence: LG Lenke, M.D., 1 Barnes Hospital Plaza, Suite 11300, St Louis, MO 63110, USA. mental manipulation in an attempt to improve the ultimate neurologic outcome in acute spinal cord injury. ${ }^{2,4,13}$

Both the primary and secondary injury cascades ultimately produce cell death both in neuronal and supporting cell tissues. It is known that cell death can occur via two morphologically distinct pathways: necrotic and apoptotic. Necrotic cell death occurs following actual mechanical disruption of cells as well as from overwhelming cellular injury that may occur during the secondary injury cascade. This potentially renders the cellular membrane incompetent with subsequent cell swelling and lysis provoking a significant inflammatory response. Necrotic cell death occurs without cellular control and thus occurs passively.

In contrast, apoptotic cell death is considered a physiological or programmed cell death that appears to be an actively regulated response by inducible cells to a specific inducing stimulus. ${ }^{5,14-18}$ The apoptotic cell stimulus may occur from the surrounding cellular environment, internal metabolism, developmental history, and/or its genome. Although necrotic cell death is a known consequence of the actual neuronal tissue damage occurring at the time of a traumatic spinal cord injury, it is unknown what part, if any, apoptotic cell death plays following acute spinal cord injury. However, the knowledge of apoptosis occurring following acute spinal cord injury could prove to be an important avenue for improved neuronal cell survival 
by blocking or limiting apoptotic cell death, which has been shown possible in a variety of tissues. ${ }^{19,20}$

Recently, the ability to accurately determine apoptotic cell death has become available using the TUNEL assay. This provides in situ labeling of internucleosomally degraded DNA which is the hallmark of apoptotic cell death. The purpose of this present investigation was to determine whether apoptotic cell death occurs in the zone of acute experimental spinal cord injury in the rat model and to determine the types of cells involved and the time course of occurrence. If apoptotic cell death can be shown to occur in acute spinal cord injury, this may provide potential treatment strategies to counteract apoptotic neuronal cell death and may prove important for maximizing neuronal cell survival following acute spinal cord injury.

\section{Methods}

Acute experimental spinal cord injury in the rat weightdrop model

An acute spinal cord injury model was utilized in this experiment and has been described previously in our laboratory. ${ }^{4}$ Sixteen, approximately 400 g, SpragueDawley adult rats were utilized for this experimentallyinduced acute spinal cord injury. The animal protocols were approved by the Washington University Animal Studies Committee (\#92371). Following appropriate intraperitoneal ketamine anesthesia and sedation, the dorsal thoracic spine of the rat was shaved, surgically prepared and draped and a mid line incision was made near the apex of thoracic kyphosis. A two-level laminectomy was performed in this region to adequately expose the thoracic spinal cord. The rats were then administered a $350 \mathrm{~g} / \mathrm{cm}$ injury (35 g weight drop at a height of $10 \mathrm{~cm}$ ) to their spinal cord using the Allen weight-drop technique at room temperature in a manner previously published in our laboratory. ${ }^{4}$ Immediately following the experimental injury, gross hemorrhage was visible beneath the dorsal surface of the dura. The rats were then awakened from anesthesia (except for those rats killed immediately following the injury - time 0 rats), and noted to be completely paraplegic in their hind limbs and tails. The rats were then killed at $30 \mathrm{~min}, 4 \mathrm{~h}, 8 \mathrm{~h}, 12 \mathrm{~h}, 24 \mathrm{~h}$, and $72 \mathrm{~h}$ following the spinal cord injury.

The spinal cords were then harvested, fixed rapidly and iced in a 10\%-neutral-buffered formalin solution followed by Bouin's solution for $24 \mathrm{~h}$, and then stored refrigerated in $70 \%$ ethanol until they were embedded in paraffin. The specimens were then adequately prepared for undergoing TUNEL assay analysis.

\section{Technique of analyzing apoptotic cell death by the TUNEL assay}

The fundamental morphologic process occurring in apoptosis is DNA fragmentation. Large fragments of
$300 \mathrm{~kb}$ and $50 \mathrm{~kb}$ DNA are first produced by endonucleolytic degradation of higher-order chromatin structured organization. Endonucleolytic cleavage at this level causes the chromatin to undergo condensation while further endonuclease activity cleaves the chromatin at linker DNA sites between nucleosomes. The ultimate DNA fragments are multimers of approximately $100 \mathrm{bp}$ nucleosomal units. The specific labeling target of the ApopTag plus (Oncor, Gaithersburg, Maryland) is the multitude of new preprime-OH DNA ends generated by the DNA fragmentation and typically found in morphologically distinct nuclei named apoptotic bodies. In contrast, normal or proliferative nuclei, which have relatively insignificant numbers of preprime-OH DNA ends do not stain with the Apop Tag plus label. Thus, visualization of in situ staining inside intact apoptotic nuclei and apoptotic bodies exactly correlates with the typical biochemical and morphologic characteristics seen in those cells undergoing apoptotic cell death.

The specific means to document apoptosis involves in situ labeling of internucleosomally degraded DNA. This involves the binding by terminal deoxynucletidyltransferase (TdT) of digoxigenin-dUTP to preprime$\mathrm{OH}$ DNA ends generated by the internucleosomal degradation of DNA (noted as the TUNEL technique). Actual visualization of digoxigenin-labeled DNA occurs by direct immunoperoxidase reaction. (ApopTag, Oncor, Gaithersburg, Maryland). The ApopTag detection kit also includes two positive control slides as well as negative control sections that are run with every block. Sham staining is performed by substituting $16 \mu \mathrm{l}$ of distilled water for TdT enzymes in the preparation of working strength of $\mathrm{TdT}$, and continuing with the staining process. This control indicates whether endogenous peroxidase is present or has been adequately mitigated by the use of a quenching reaction.

\section{Confirmation of histologic chronology of apoptotic} neuronal cell death following acute spinal cord injury Acute spinal cord injury tissue specimens were obtained at time $0,30 \mathrm{~min}, 4 \mathrm{~h}, 8 \mathrm{~h}, 12 \mathrm{~h}, 24 \mathrm{~h}$ and $72 \mathrm{~h}$ following the acute experimental spinal cord injury. Serial axial and sagittal thin sections were prepared for all specimens using hematoxylin and eosin ( $\mathrm{H}$ and $\mathrm{E}$ ) staining for immunohistology. Standard light microscopy and differential contrast interference light microscopy were utilized. Brown-colored intranucleosomal and intra-apoptotic body staining of the cells confirmed the presence of apoptotic cell death in the tissues examined.

\section{Results}

The ApopTag detection analysis demonstrated a chronologically-specific apoptotic cell death occurring in the acute spinal cord injury rat model throughout both neuronal and supporting cellular tissues. As 
anticipated, spinal cord tissue harvested at time 0 immediately following the acute spinal cord injury did not demonstrate any evidence of apoptotic cell death on either low or high magnification light microscopy (Figure 1). Thus, there does not appear to be any (or marginal) inherent apoptotic cell death occurring in spinal cord tissue at the time of an acute spinal cord

a

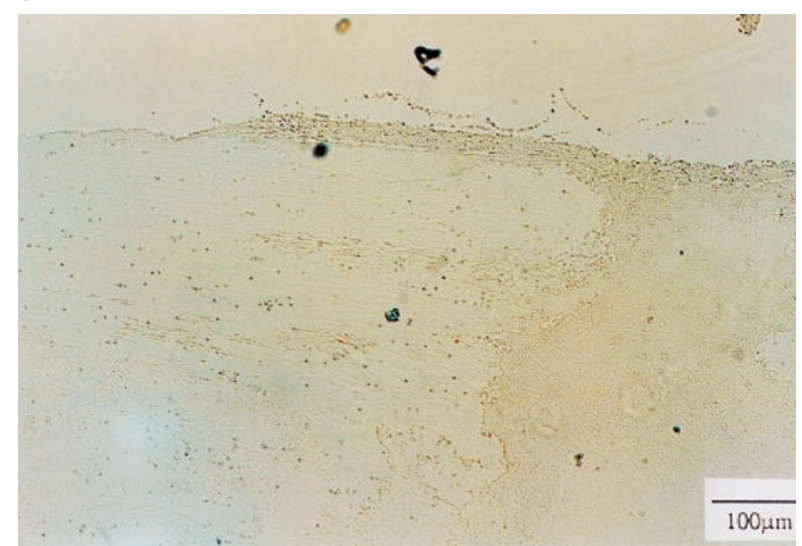

b

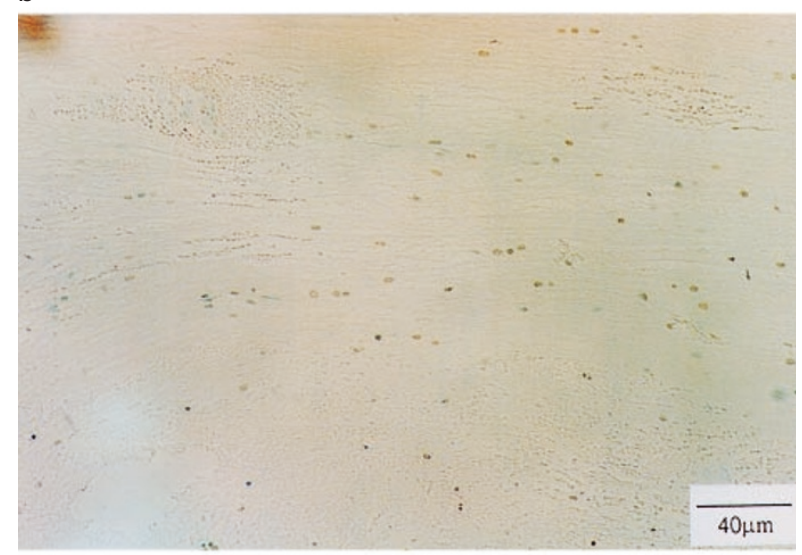

C

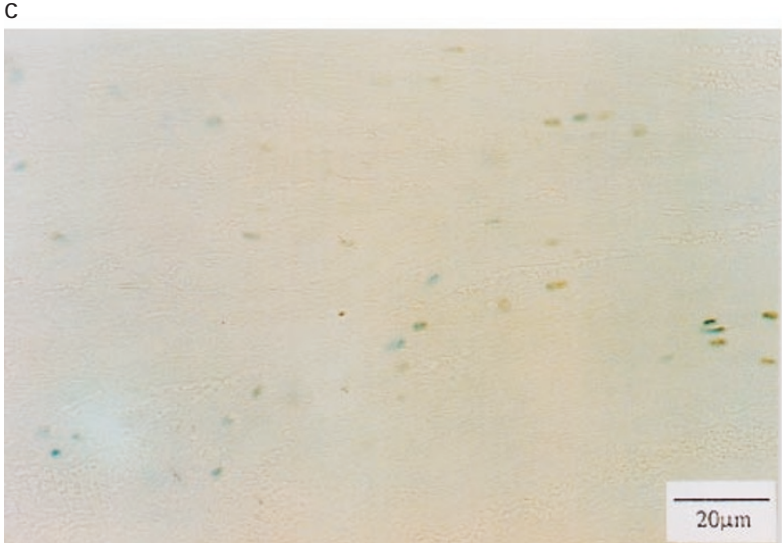

Figure 1 Time course $-0 \mathrm{~h}$ post experimental spinal cord injury (a) $40 \times$, (b) $100 \times$ and (c) $200 \times$ magnification views of spinal cord tissue demonstrate the absence of any brown intranuclear staining confirming lack of apoptosis occurring during normal tissue homeostasis injury. Similarly, the time $30 \mathrm{~min}$ specimens post spinal cord injury in both low and high power demonstrated no distinct evidence of apoptotic activity within the cells in the zone of spinal cord injury (Figure 2). This

a

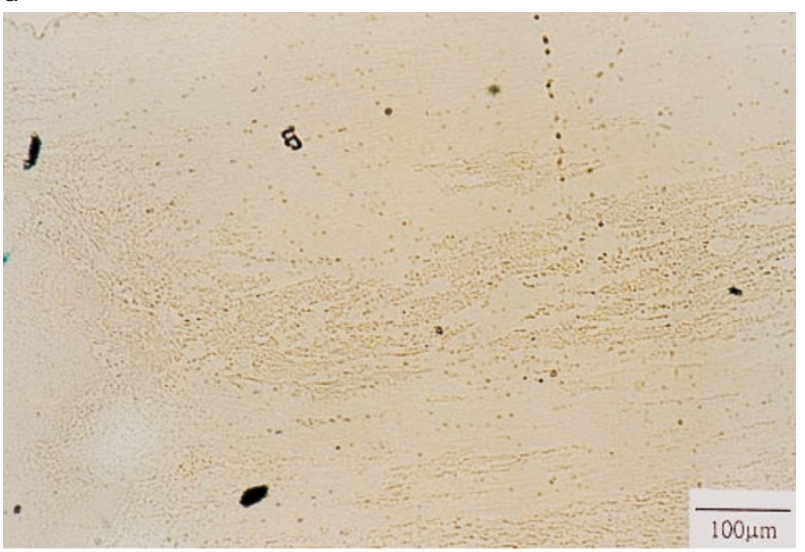

b

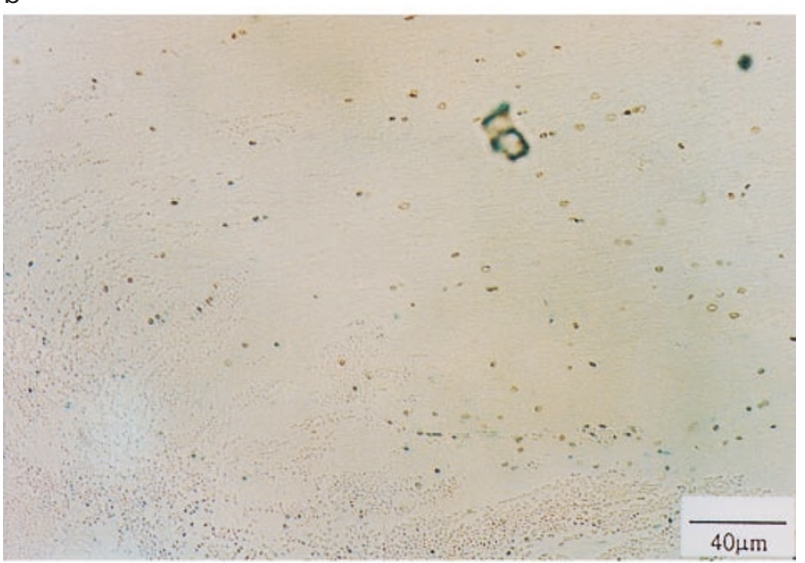

C

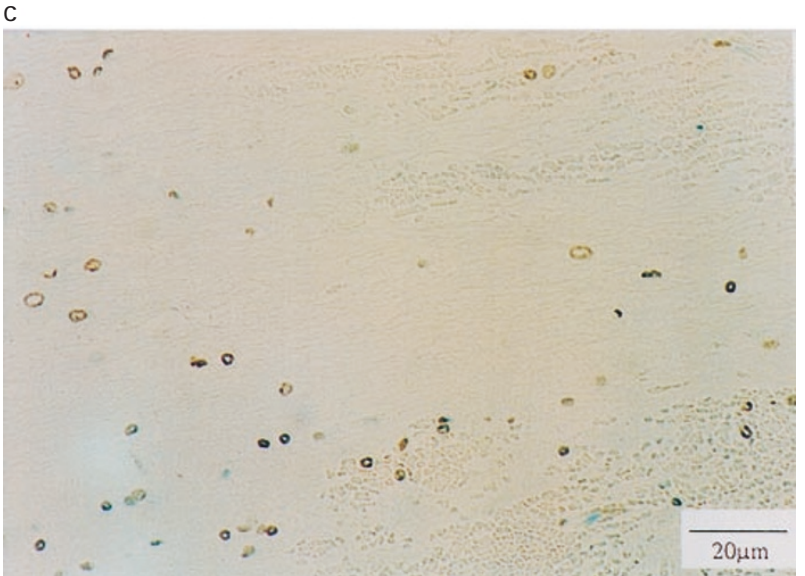

Figure 2 Time course - $30 \mathrm{~min}$ following experimental spinal cord injury (a) $40 \times$, (b) $100 \times$ and (c) $200 \times$ magnification views of spinal cord tissue show a few brown staining cells primarily in a periphery. This documents a paucity of apoptosis occurring due to the absence of any true intranuclear staining of apoptotic bodies 
was confirmed again by a lack of brown intranuclear staining present in the cells.

However, in the next time point examined, the time $4 \mathrm{~h}$ specimens, there was a marked level of apoptotic staining present seen on low and high power light microscopy (Figure 3). The low magnification $(40 \times)$ demonstrates the brown staining cells scattered throughout the spinal cord tissue. On higher magnification $(200 \times)$, distinct brown intracellular staining is noted, indicative of positive apoptotic staining. On higher magnification $(400 \times)$ distinct intranuclear staining regions are identified. Abundant supporting cellular staining is noted as well, with a fair proportion (approximately 25\%) of cells visualized staining for apoptotic nuclear DNA fragments. The time $4 \mathrm{~h}$ assessments showed the highest quantity of apoptotic cell staining, which included both neuronal and glial cells. Although the time point $8 \mathrm{~h}$ (Figure 4) showed a similarly constant staining pattern of apoptotic cells, it was slightly less than the $4 \mathrm{~h}$ specimen which appeared to have the peak activity of apoptotic cells as seen on both low and high power magnification specimens. By time point $24 \mathrm{~h}$ post spinal cord injury, no discernable apoptotic activity was visualized, and this lack of staining was also noted at the time point $72 \mathrm{~h}$ following spinal cord injury (Figures 5 and 6).

Thus, histologic analysis following the TUNEL assay specific for apoptotic cell death demonstrated a tightly regulated time course of occurrence. The absence of positive staining at time 0 and in the negative control specimens confirms the absence of marked apoptotic cell death occurring in normal spinal cord tissue. Peak occurrence of apoptotic nuclear staining at $4 \mathrm{~h}$, and to a slightly lesser extent $8 \mathrm{~h}$, post acute spinal cord injury provides novel evidence for the occurrence of an apoptotic cell death mechanism inherent to the secondary injury cascade of acute spinal cord injury. The complete absence of apoptotic cell death at the immediate zone of spinal cord injury occurring at 24 and $72 \mathrm{~h}$ post injury reinforces the strict time dependence of neuronal and supporting cell apoptotic death and strongly suggests either an external or internal time dependent stimuli for initiation of apoptotic cell death following acute spinal cord injury.

We were able to demonstrate this time specificity because of the unique labeling of the ApopTag

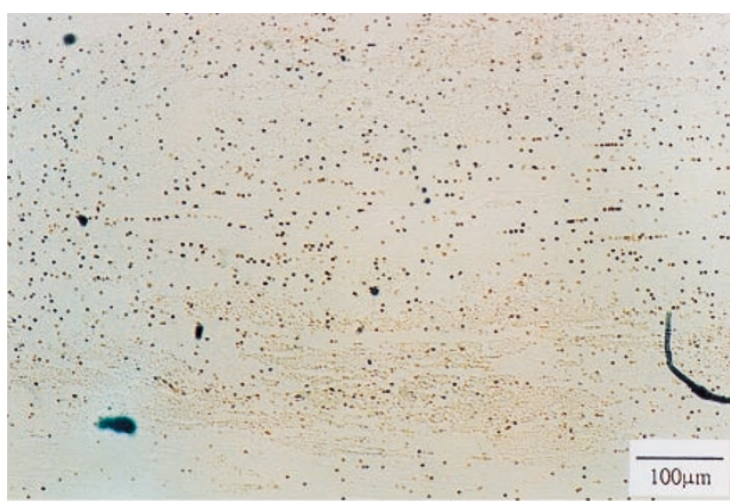

C

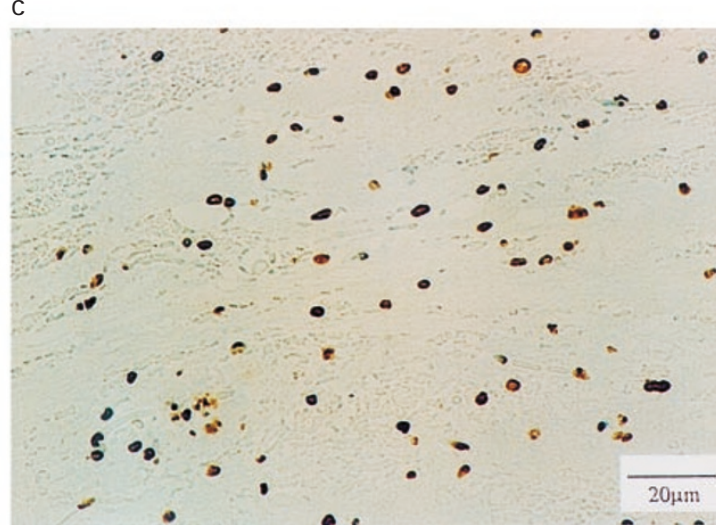

b

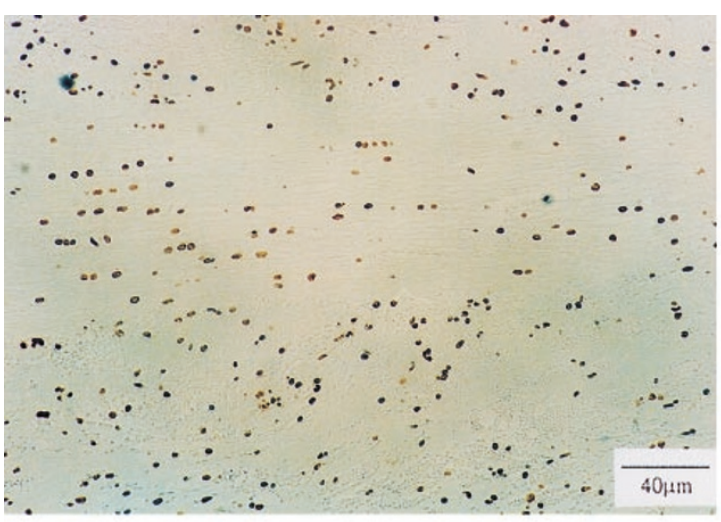

d

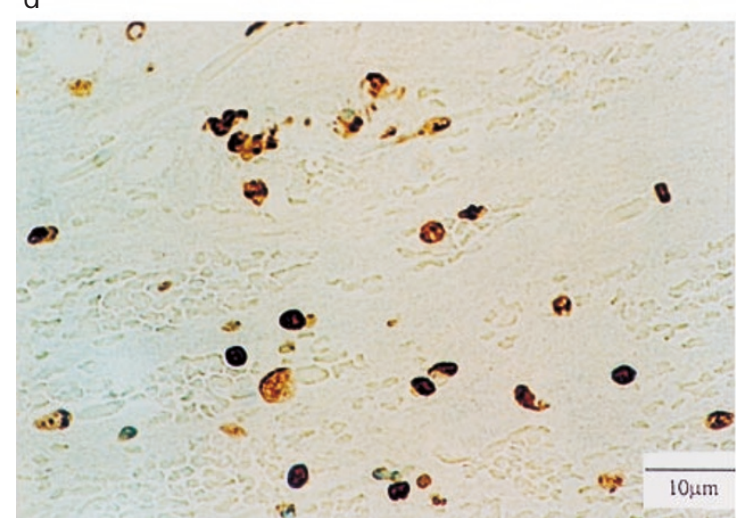

Figure 3 Time course $-4 \mathrm{~h}$ post experimental spinal cord injury (a) $40 \times$, (b) $100 \times$, (c) $200 \times$ and (d) $400 \times$ magnification views of spinal cord tissue demonstrate the marked increase in brown intranuclear staining present throughout the tissues examined. On higher magnification, both supporting glial as well as neuronal cells are noted to be staining, and distinct intranuclear staining is visible on the $400 \times$ high power (d) specimens. This confirms the occurrence of apoptosis and demonstrate the time-dependent nature of its onset $4 \mathrm{~h}$ post-injury 
peroxidase system. We used labeling to previously cleaved intranuclear DNA which can only occur during that time point between actual cleavage of the DNA and cell dissolution which occurs in a relatively quick and silent manner by surrounding macrophages. Thus, those cells previously undergoing apoptotic cell death at $4-8 \mathrm{~h}$, will not be stained at $24 \mathrm{~h}$ because the previously cleaved and apoptotically stainable DNA fragments have undergone sufficient degradation that the TdT entity cannot attach to the free OH-DNA fragments. Thus, apoptotic cell death proceeds in an orderly fashion within a time dependent interval of cleaved DNA exposure for staining confirmation of apoptosis.

\section{Conclusions}

This study documents the occurrence of apoptotic neuronal cell death resulting from an acute experimental spinal cord injury. This is in direct contrast to the previously accepted role of necrotic cell death which is quite morphologically and biochemically distinct from apoptotic cell death. Necrotic cell death occurs passively resulting from the actual tissue mechanical damage and resultant release of destructive lysozymes, ion fluxes, and disturbed cell membranes producing an inflammatory response that has long been understood to be the sole component of neuronal tissue death and the ultimate clinical neurologic ramifications of acute spinal cord injury.

In contradistinction to necrotic cell injury, apoptosis is associated with physiological or programmed cell death. ${ }^{14,15}$ Apoptosis is an actively regulated response which occurs following some inducible external or internal stimuli to various cells. There are a variety of morphological criteria which distinguish apoptotic from necrotic cell death. Apoptotic cell death occurs a single cell at a time, while necrotic cells normally die in groups. Although cell membranes may undergo blebbing during apoptotic cell death, they do not lose their structural integrity as do cells undergoing necrotic cell death. Cells undergoing apoptotic death actually shrink forming apoptotic cell bodies which contain the cleaved DNA which is stained on the TUNEL assay technique utilized to confirm apoptosis in this study. In contrast, necrotic cells swell and lyse which insights a significant inflammatory response. Thus, although both apoptotic cell bodies and necrotic cells may be phagocytosed by tissue macrophages, apoptotic cell bodies do not incite any type of a

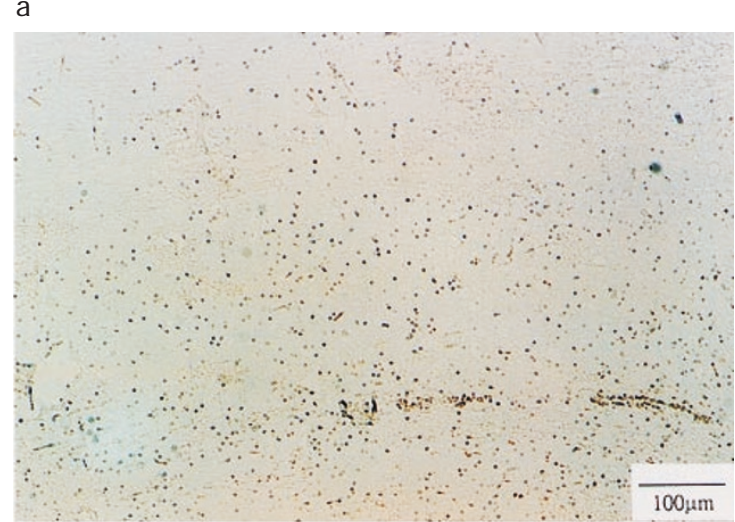

C

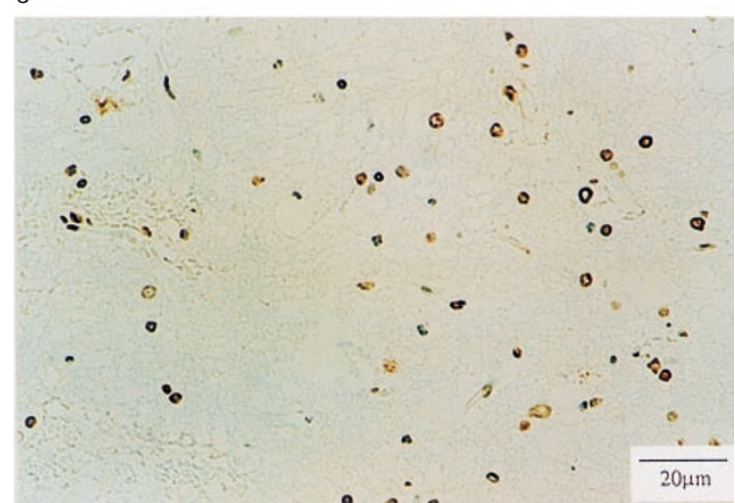

b

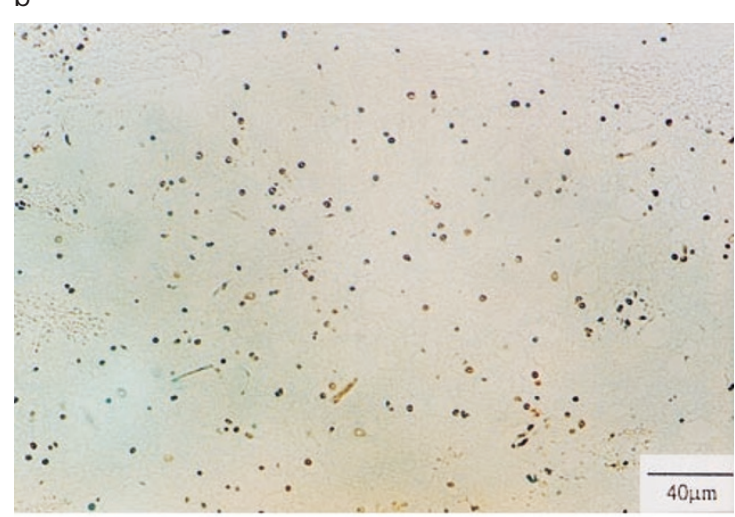

d

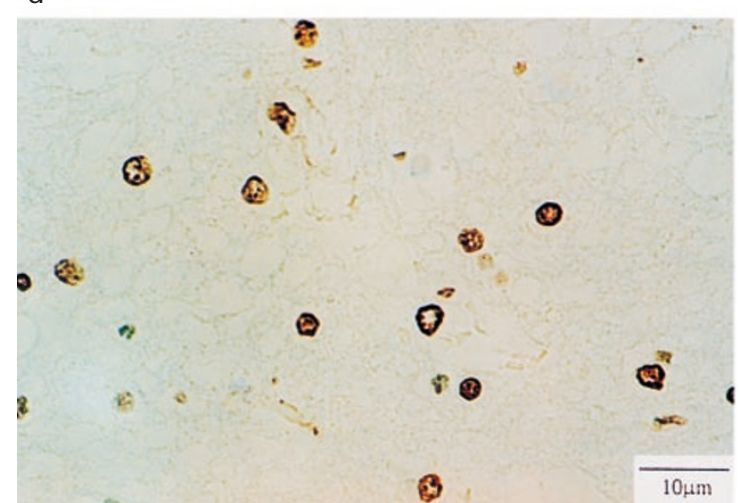

Figure 4 Time course $-8 \mathrm{~h}$ post experimental spinal cord injury (a) $40 \times$, (b) $100 \times$, (c) $200 \times$ and (d) $400 \times$ magnification views of spinal cord tissue show continued apoptotic activity present throughout the specimens though to a slightly less quantifiable degree than the $4 \mathrm{~h}$ specimens. However, continued presence of intranuclear apoptotic brown staining bodies as seen on the higher magnification views $(\mathbf{c}, \mathbf{d})$ confirms the continued occurrence of apoptosis at the time $8 \mathrm{~h}$ point 
inflammatory response and thus undergo a 'silent' cell death.

At the molecular level, there are many distinct morphologic and biochemical changes occurring during apoptosis including chromatin condensation,

a

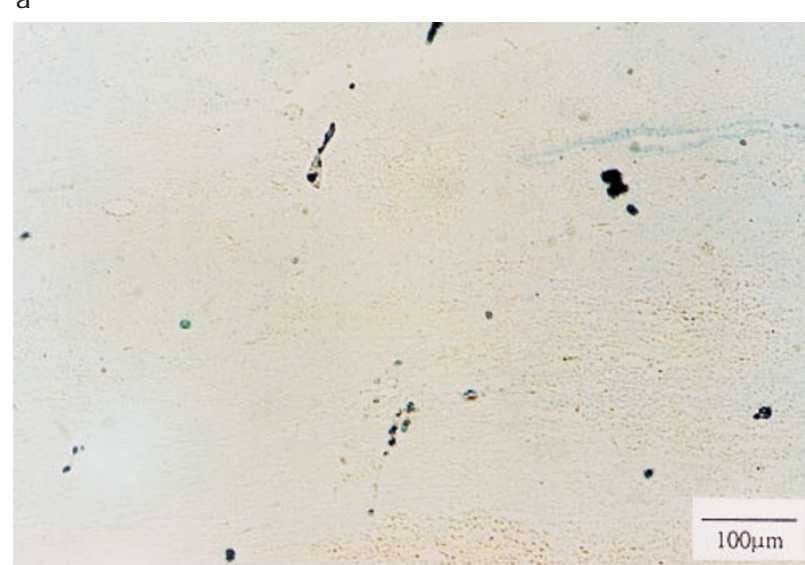

b
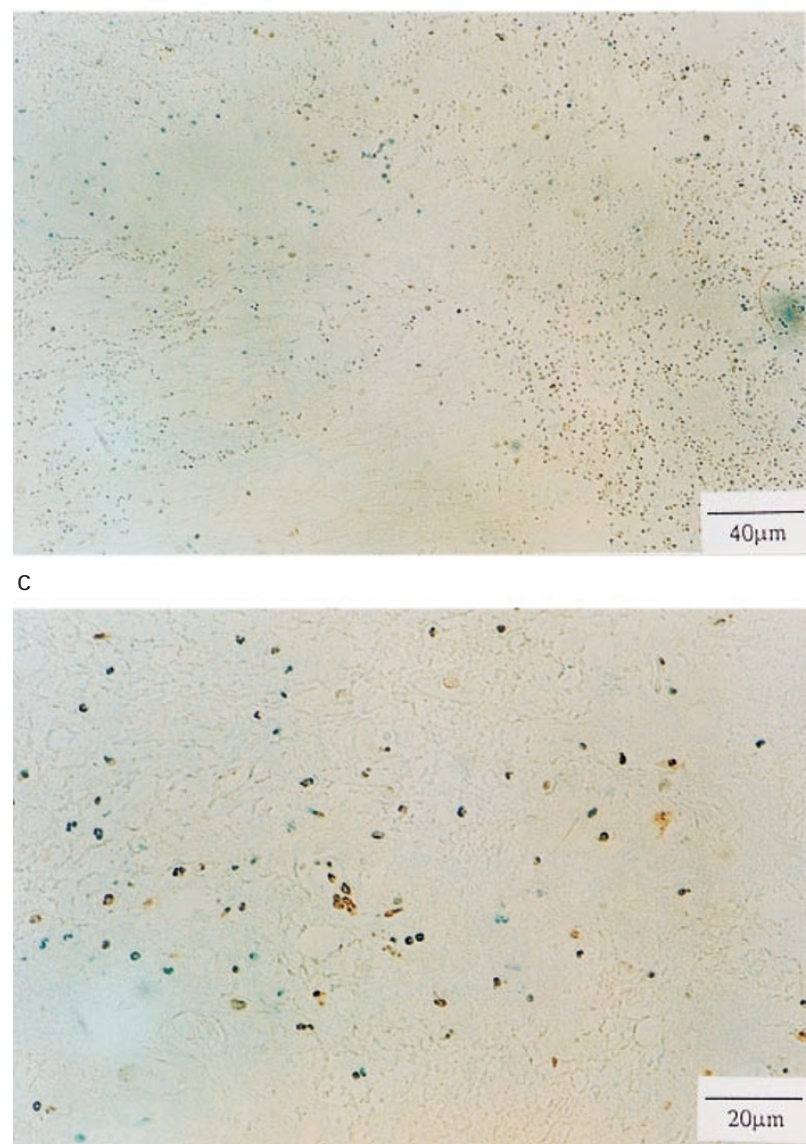

Figure 5 Time course $-24 \mathrm{~h}$ post experimental spinal cord injury (a) $40 \times$, (b) $100 \times$, and (c) $200 \times$ magnification views of spinal cord tissue demonstrate marked decrease in the level of apoptosis with nearly complete dissolution of any apoptotically stained intranuclear bodies. This is in marked contrast to the $4 \mathrm{~h}$ and $8 \mathrm{~h}$ specimens and more consistent with the time 0 and 30 min specimens
DNA fragmentation into oligonucleosome-sized fragments, and the compaction of chromatin into uniformly dense masses. The constant biochemical event which occurs in apoptosis is the activation of an endonuclease, which cleaves DNA at internucleosomal

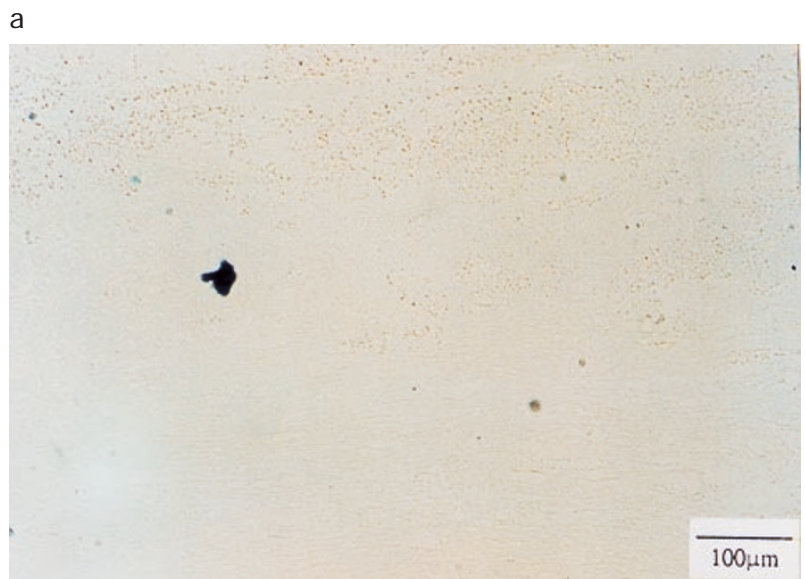

b

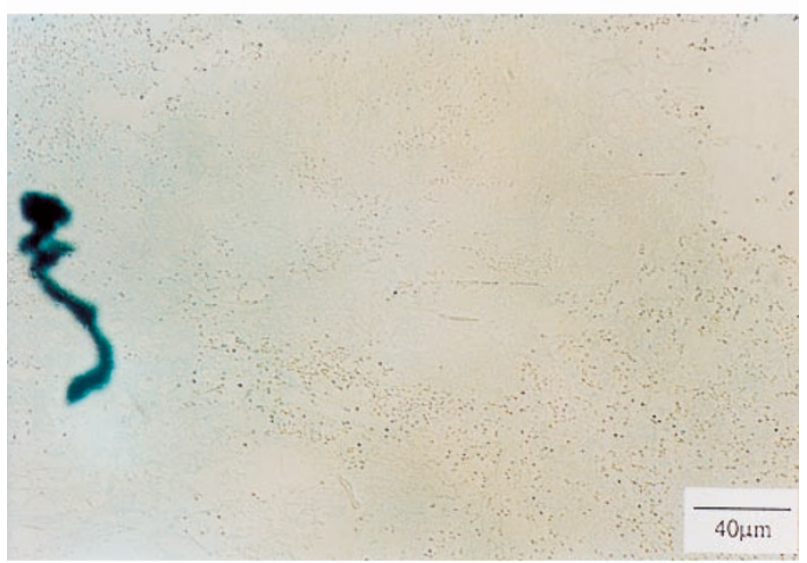

C

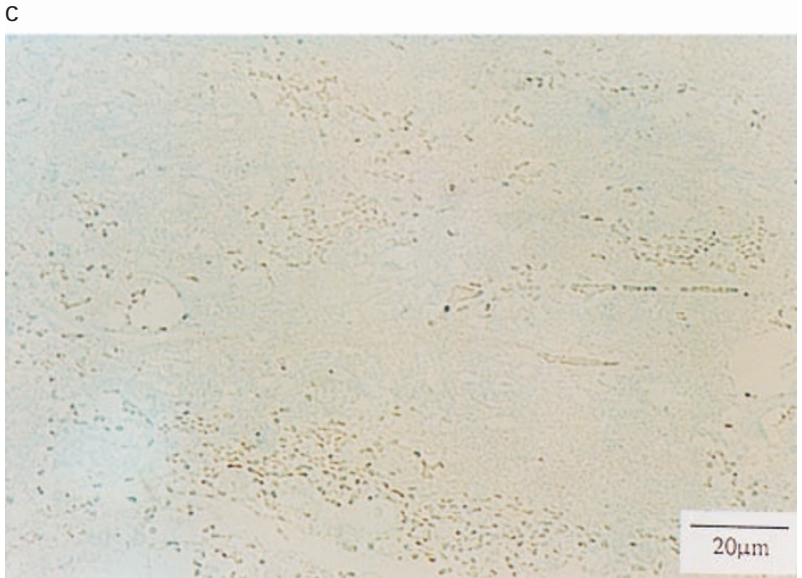

Figure 6 Time course $-72 \mathrm{~h}$ post experimental spinal cord injury (a) $40 \times$, (b) $100 \times$, and (c) $200 \times$ magnification views of spinal cord tissue at the zone of injury demonstrate complete absence of any type of brown apoptotic staining in any of the specimens consistent with the time 0 specimens (see Figure 1) 
linker sites. This allows attachment by the TUNEL assay TdT which is specific for the free OH-DNA fragments produced.

The biochemical criteria for distinguishing apoptotic from necrotic cell death are also quite well established. Apoptotic cell death is induced by physiologic stimuli, either external or internal, while necrotic cell death arises from nonphysiologic disturbances, as in the actual tissue disruption following the $350 \mathrm{~g} / \mathrm{cm}$ weightdrop performed on the spinal cord tissue in our model. Apoptotic cell death is a tightly regulated process with a sequence of activation steps that requires energy and specific macromolecular synthesis as well as de novo gene transcription. ${ }^{21}$ This proceeds the nonrandom oligonucleosomal length DNA fragmentation which is the common final pathway of eventual apoptotic cell death. In contrast, during necrotic cell death there is no energy requirements because there is no de novo gene transcription, and thus no new protein or nucleic acid synthesis which occurs. ${ }^{1,15}$ The cellular DNA is randomly digested following cell lysis by macrophages which are solicited following the inflammatory response.

We elected to use the TUNEL labeling technique to evaluate for the presence of apoptotic cell death following acute spinal cord injury because of the high sensitivity and specificity of this technique. ${ }^{22}$ Visualization of small percentages of stained apoptotic cells yields biologically significant data that is often unobtainable by examination of histochemically stained tissue or by DNA ladder assays. The reason for this occurrence is that DNA fragmentation in apoptotic cells is followed by cell death and quick removal from the tissue in a 'silent' fashion within several hours. Thus, the appearance of the characteristic apoptotic bodies is quite fleeting, making assessment of apoptosis by cell morphology quite difficult. This is also why we did not see apoptotically stained cells at the $24 \mathrm{~h}$ and $72 \mathrm{~h}$ post-injury time points, even though the $4 \mathrm{~h}$ and $8 \mathrm{~h}$ specimens had such strong staining. Prompt removal of apoptotic cell bodies appears to proceed in an organized and efficient manner from adjacent other normal cells as well as by macrophages. $^{21}$

Apoptotic programmed cell death has been shown to occur in a variety of tissues and cellular systems including: the immature immune system, ${ }^{14}$ embryonic development, in human atherosclerotic vascular lesions, ${ }^{20}$ in human leukemia cells, ${ }^{17}$ and in a variety of cancers including lymphoma, oral cancer and in during normal tissue turnover. ${ }^{21}$ Although genes have been identified which appear to regulate apoptosis, the essential biochemical events leading up to apoptotic cell death remain basically unknown. Recent research points to an interrelationship between the cell cycle, transformation and programmed cell death. Thus, apoptosis is considered to be an actively regulated response by inducible cells to a specific inducing stimulus, either external or internal. As an example, a variety of highly selective cytotoxic agents may induce apoptosis only in specific cells having relevant response pathways. The delineation of these stimuli as well as the inherent cellular pathways remain unknown.

The knowledge of apoptotic cell death occurring following acute spinal cord injury may provide for additional strategies to limit neuronal cell death and potentially improve neurologic function. Various antiapoptotic agents have been shown to limit apoptotic cell death and may therefore limit neural tissue death in the zone of spinal cord injury. ${ }^{19,23}$

One such anti-apoptotic agent, the oncogene Bcl-2, has already been shown to improve histologic survival following an acute experimental spinal cord injury in the rat model. ${ }^{24} \mathrm{Bcl}-2$ overexpression was produced invivo following introduction of the $\mathrm{Bcl}-2$ gene via a recombinant adenovirus vector prior to the same experimental spinal cord injury administered in this study. Bcl-2 appears to inhibit apoptotic cell death by regulating an antioxidant pathway that limits free radical generation. ${ }^{11,16,25}$ The subsequent decrease in reactive oxygen species which are known to be detrimental to cellular function, may play an important role in the secondary injury cascade of spinal cord injury. 26,27

Just prior to submission of this manuscript, a report confirming apoptotic cell death following spinal cord injury in rats and monkeys was noted. ${ }^{28}$ This report also utilized the TUNEL assay to document apoptotic DNA fragmentation following an acute, experimental spinal cord injury. These authors noted apoptotic nuclei present beginning at $6 \mathrm{~h}$ ( $v s 4 \mathrm{~h}$ in our study) and also noted apoptosis occurring away from the zone of spinal cord injury at $24 \mathrm{~h}$ and beyond (up to 3 weeks) post contusion. Thus, both studies agree on the time-dependent occurrence of apoptosis at the zone of spinal cord injury beginning at $4-6 \mathrm{~h}$ post-injury and absent by 24 h. However, Crowe and associates also examined more distant sites where apoptosis was noted from 8 days to 3 weeks post-injury and thus may play an important role in the chronic demyelination process which occurs at more distant sites.

In this preliminary study, we documented a chronologically specific time course of apoptotic cell death occurring acute experimental spinal cord injury in the rat model. This may provided novel strategies to limit cell death in the zone of spinal cord injury by utilizing various anti-apoptotic agents such as the oncogene Bcl-2. Further investigation to more precisely quantify both neuronal and supportive cell apoptosis appears necessary and may aid in the development of neural protective strategies which combat apoptotic cell death.

\section{Acknowledgements}

This study was supported by Paul R Manske, MD and grant \#15951 from Shriners Hospital. 


\section{References}

1 Collins WF, Piepmeir J, Ogle E. The spinal cord injury problem. A review. Central Nerv Syst Trauma 1986; 3: 317-331.

2 Anderson TE, Stokes BT. Experimental models for spinal cord injury research. Physical and physiological considerations. $J$ Neurotrauma 1992; 9: S135-S142.

3 Hovda D, Becker D, Katayama Y. Secondary injury in acidosis. Neurotrauma 1992; 9: S47-S60.

4 O'Brien MF, Lenke LG, Lou J, Bridwell KH, Joyce ME. Astrocyte response and transforming growth factor-b localization in acute spinal cord injury. Spine 1994; 19: $2321-2330$.

5 Willie AH, Kerr JFR, Currie AR. Cell death. The significance of apoptosis. Int Rev Cytol 1980; 68: 251-306.

6 Banick N, Hogan E, Hsu E. The multimolecular cascade of spinal cord injury. Neurochem Pathol 1987; 7: $57-77$.

7 Tator $\mathrm{CH}$, Fehlings MG. Review of the secondary injury theory of acute spinal cord trauma with emphasis on vascular mechanisms. J. Neurosurg 1991; 75: 15-26.

8 Blight A. Macrophages and inflammatory damage in spinal cord injury. J Neurotrauma 1992; 9: S83-S90.

9 Braunwald E, Kloner R. Myocardial reperfusion: a double-edge sword? J Clin Invest 1985; 76: $1713-1719$.

10 Blaughler JM, Hall ED. Involvement of lipid peroxidation in CNS injury. J Neurotrauma 1992; 9: S1-S6.

11 Chen FD, Schneider GE, Martinou J-C, Tonegawa S. Bcl-2 promotes regeneration of severed axons in mammalian CNS Nature 1997; 385: $434-439$.

12 Hall ED, Braughler JM, McCall JM. Antioxidant effects in brain and spinal cord injury. J Neurotrauma 1992; 9: S165-S172.

13 Wrathall JR, Pettegrew PK, Harvey F. Spinal cord contusion in the rat. Production of graded, reproducible, injury groups. Exp Neurol 1985; 88: $123-124$.

14 Abrams JM, White K, Fessler LI, Steller H. Programmed cell death during Drosophila embryogenesis. Development 1993; 117: $29-43$.

15 Bargmann CI. Death from natural and unnatural causes. Elegant studies of the nematode are providing answers to the question of how programmed cell death and neurodegeneration are regulated. Curr Biol 1991; 1: 388 - 390.
16 Vaux DL, Cory S, Adams JM. Bcl-2 promotes the survival of haemopoietic cells and cooperates with c-myc to immortalize preB cells. Nature 1988; 335: 440-442.

17 Williams GT. Programmed cell death. Apoptosis and oncogenesis. Cell 1991; 65: $1097-1098$.

18 Williams GT, Smith CA, McCarthy NJ, Grimes EA. Apoptosis. Final control point in cell biology. Trends Cell Biol 1992; 2: 263 267.

19 Allsopp TE, Wyatt S, Paterson HF, Davies AM. The protooncogene $\mathrm{Bcl}-2$ can selectively rescue neurotrophic factordependent neurons from apoptosis. Cell 1993; 73: 295-307.

20 Bjorkerud S, Bjorkerud B. Apoptosis is abundant in human atherosclerotic lesions, especially in inflammatory cells (macrophages and $\mathrm{T}$ cells), and may contribute to the accumulation of gruel and plaque instability. Am J Pathol 1996; 149: 367-380.

21 Kerr JFR, Wyllie AH, Currie AR. Apoptosis. A basic biological phenomenon with wide-ranging implications in tissue kinetics. $\mathrm{Br}$ J Cancer 1972; 26; $239-257$.

22 Gavrieli Y, Sherman Y, Ben-Sasson SA. Identification of programmed cell death in situ via specific labeling of nuclear fragmentation. J Cell Biol 1992; 119: 493-501.

23 Hockenberry DM, Oltavi ZN, Yin X-M, Milliman CL, Korsmeyer SJ. Bcl-2 functions in an antioxidant pathway to prevent apoptosis. Cell 1993; 75: $241-251$

24 Lou J, Lenke LG, Xu F, O'Brien MF. In-vivo Bcl-2 oncogene neuronal expression in the rat spinal cord. Accepted to Spine, June, 1997.

25 Korsmeyer SJ. Bcl-2. A repressor of lymphocytic death. Immunology Today 1992; 13: 283-288.

26 Hall ED, Yonkers PA, Andrus PK, Cox JW, Anderson DK. Biochemistry and pharmacology of lipid antioxidants in acute brain and spinal cord injury. J Neurotrauma 1992; 9: S425-S442.

27 Kane DJ et al. Bcl-2 inhibition of neural death. Decreased generation of reactive oxygen species. Spinal cord injuryence 1993; 262: $1274-1277$.

28 Crowe MJ, Bresnahan JC, Shuman SL, Masters JN, Beattie MS. Apoptosis and delayed degeneration after spinal cord injury in rats and monkeys. Nature Med 1997; 3: 73-76. 